\title{
Asenkron Motor Geometrisinin Motor Yol Alma Süresine Etkilerinin İncelenmesi
}

\section{Investigation of the Effects of Induction Motor Geometry on Motor Starting Time}

\author{
Mehmet Murat Tezcan ${ }^{1}$, Asım Gökhan Yetgin ${ }^{2 *}$ \\ Geliş / Received: 18/03/2021 \\ Revize / Revised: 24/08/2021 \\ Kabul / Accepted: 13/09/2021 \\ ÖZ \\ Asenkron motorlar endüstride en çok kullanılan motor olması nedeniyle, farklı uygulamalarda motorun yol alma \\ süresi büyük önem kazanmaktadır. Özellikle ağır yüklerin yol alması sırasında çekilen büyük akımlar motorda \\ çeşitli sorunlara neden olmaktadır. Asenkron motorda yol alma süresinin ve çekilen akımın sınırlandırılması için \\ farklı yöntemler kullanılmaktadır. Bu çalışmada asenkron motorun rotor oluk yüksekliğinin, hava aralığı boyunun \\ ve farklı rotor oluk geometrilerinin motorun yol alma süresine etkileri araştırılmıştır. RMxprt programı ile motor \\ tasarımı yapılmış, daha sonrasında Rmxprt programından elde edilen parametreler kullanılarak MATLAB- \\ Simulink modeli oluşturulmuş ve motorların yol alma süreleri elde edilmiştir. Ayrıca her bir motor modeli için \\ devir sayısındaki salınımlar incelenmiştir. Modellemelerde $13 \mathrm{~kW}, 400 \mathrm{~V}, 3$ fazlı sincap kafesli asenkron motor \\ kullanılmıştır.
}

Anahtar Kelimeler- Asenkron Motor, Yol Alma Süresi, Rotor Oluk Yüksekliği, Hava Aralığı Boyu, Rotor Oluk Geometrisi

\begin{abstract}
Since induction motors are the most used motors in the industry, the starting time of the motor is of great importance for different applications. Especially large currents drawn during the movement of heavy loads cause various problems in the motor. Different methods are used to limit the starting time and the current drawn in the induction motor. In this study, the effects of rotor slot height, air gap length, and different rotor slot geometries on induction motor's starting time were investigated. Motor design was made with the RMxprt program, and MATLAB-Simulink model was created using obtained parameters from Rmxprt, and then the starting times of the motors were obtained. In addition, the oscillations in the number of speeds were examined for each motor model. $13 \mathrm{~kW}, 400 \mathrm{~V}, 3$ phase squirrel cage induction motor was used in the models.
\end{abstract}

Keywords- Induction Motor, Starting Time, Rotor Slot Height, Air Gap Length, Rotor Slot Geometry

1İletişim: murat.tezcan@dpu.edu.tr (https://orcid.org/0000-0002-5390-4527)

Elektrik-Elektronik Mühendisliği, Kütahya Dumlupınar Üniversitesi, Mühendislik Fakültesi, Merkez Kampüs, Kütahya

2*Sorumlu yazar iletișim: agyetgin@mehmetakif.edu.tr (https://orcid.org/0000-0003-3971-0504)

Elektrik-Elektronik Mühendisliği, Burdur Mehmet Akif Ersoy Üniversitesi, Müh.-Mim. Fakültesi, İstiklal Yerleşkesi, Burdur 


\section{GíRiş}

Asenkron motorlar üretim maliyetlerinin düşük olması, geniş güç aralığı ve güvenilir çalışma gibi nedenlerden dolayı ev aletlerinde ve endüstriyel uygulamalarda sıklıkla kullanılmaktadırlar [1]. Ayrıca birkaç yüz W seviyesindeki güçlerden, MW seviyesindeki güçlere kadar imal edilebilmektedirler. Sabit güç, sabit moment, hızla orantılı moment artışı, hızın karesiyle orantılı moment artışı ve hızla ters orantılı moment azalması gibi değişik moment-hız karakteristiklerine dayalı farklı tip endüstriyel uygulamalar için de kullanılabilmektedir [2].

Asenkron motorların farklı uygulamalarda kullanılması özellikle ağır yüklerin hareket ettirilmesi (yol alması) noktasında büyük önem kazanmaktadır. Motora bağlı olan bir yükün hareket ettirilmesi için motor yol alma momentinin yük momentinden büyük olması gerekmektedir. Ayrıca yükün hareket ettirilmesi ve motorun nominal devir sayısına ulaşması için geçen süre oldukça önemlidir. Bu süre zarfında motorun devir sayısında bir salınım meydana gelmektedir ve bu salınım motorda titreşimlere neden olmaktadır. Doğrudan moment kontrolü [3], skaler denetim [4], dolaylı alan yönlendirmeli kontrol [5] gibi çeşitli kontrol yöntemleri ile bu salınım minimize edilebilmektedir ve motorun daha kısa sürelerde yol alması sağlanabilmektedir.

Asenkron motorların yol alması, motorun durağan pozisyonundan nominal çalışma hızına kadar olan geçici bir süreçtir. Bu periyotta motorun devir sayısı, akım ve momentte değişiklikler meydana gelmektedir. Motor şebekeye bağlandığı anda sekonderi kısa devre edilmiş bir transformatör gibi davranır ve bu anda kayma değeri 1' e eşit olur. Kayma değerinin 1 olması motorun empedansının minimum seviyede olmasına neden olur. Bu durumda motorun yol alma esnasındaki akım değeri çok yüksek çıkar. Yol alma esnasındaki akım değerinin büyük olması beraberinde bazı problemleri de meydana getirmektedir. Çok uzun yol alma süreleri, akımın yüksek olmasından dolayı ve sıcaklık değerinin yol alma süresi ile akımın karesine bağlı olması nedeniyle motorda sıcaklık artışına neden olmaktadır [6]. Bu sıcaklık artışı izolasyon malzemelerinin daha hızlı bir şekilde zarar görmesine ve buna bağlı olarak motorun çalışma ömrünün kısalmasına neden olmaktadır [7]. Ayrıca sıcaklık artışı sargı direnç değerinin artması ve motorun performansının azalması ile sonuçlanmaktadır. Bu sebeple motorlardaki yol alma süresinin motoru tehlikeye atacak kadar uzun sürmemesi gerekmektedir.

Popa vd. üç fazlı sincap kafesli bir asenkron motor tarafından sürülen sabit moment dirençli bir iş makinesinin yol alma süresinin hesabını analitik olarak hesaplamışlardır. Hesaplamaları basitleștirilmiş Kloss denklemini kullanarak yapmışlardır. Elde edilen sonuçlara göre kullanılan yöntemin daha hızlı ve hata payının daha düşük olduğunu belirtmiş̧lerdir [8]. Aree çalışmasında büyük güçlü asenkron motorların yol alma zamanlarını, motorun moment-devir sayısı eğrisini, motor üretici verilerini kullanarak tahmin edilmesi prensibine dayanarak doğru bir şekilde hesaplanabileceğini ifade etmiştir [9]. Calasan çalışmasında doğrudan şebekeden beslenen üç fazlı bir asenkron motorun yüksüz çalışma şartlarında motor hızının ve yol alma süresinin hesabını gerçekleştirmiş̧ir. Asenkron motorun eşdeğer devre parametrelerini ve moment formülasyonunu kullanarak motorun zaman-hız bağlantılarını analitik olarak ifade etmiştir [10]. Grover ve Mankar çalışmalarında üç fazlı bir asenkron motorun yol alma anındaki moment, akım ve devir sayısı eğrilerinin değişimini direk şebeke bağlantı yapılarak, yıldız-üçgen yol vererek ve oto transformatör gibi üç farklı yöntem ile incelemişlerdir. En kısa sürede devir sayısına ulaşan yöntemin yıldız-üçgen yol verme yöntemi olduğu ifade edilmiştir [11]. Kim çalışmasında, sincap kafesli bir asenkron motorun yol alma karakteristiklerini, rotor malzemesine ve farklı rotor oluk şekilleri için analiz etmiştir. Analizler sonlu elemanlar yöntemi kullanılarak yapılmış ve farklı kullanım amaçları ve kapasitesi için uygun tasarım verileri elde edilmiştir [12].

Bu çalışmada asenkron motorlarda rotor oluk yüksekliğinin, hava aralığı boyunun ve farklı rotor oluk geometrilerinin motorun yol alma süresini nasıl değiştirdiği araştırılmıştır. Çalışma asenkron motorun herhangi bir kontrol bloğu kullanılmaksızın devir sayısındaki salınımların farklı oluk yüksekliği ve geometrileri ile hava aralığı uzunluğunun etkilerini açıklaması noktasında katkı sağlayacaktır. Modellemeler ANSYS Maxwell-RMxprt [13] ve Matlab Simulink [14] programları kullanılarak yapılmıştır. Modellemelerde $13 \mathrm{~kW}, 400 \mathrm{~V}, 50 \mathrm{~Hz}, 4$ kutuplu, 3 fazlı sincap kafesli bir asenkron motor kullanılmıştır. Modellemelerde ilk aşamada RMxprt programı ile motorun tasarımı gerçekleştirilmiştir. Elde edilen stator ve rotor sargı dirençleri $\left(R_{I}\right.$ ve $\left.R_{2}\right)$ ile kaçak reaktans $\left(X_{1}\right.$ ve $\left.X_{2}\right)$ değerleri, mıknatıslanma reaktansı $\left(X_{m}\right)$ gibi parametreler Matlab Simulink programına aktarılmıştır. Simulink programında her bir motor modelinin devir sayısı-yol alma süresi grafikleri elde edilmiş ve en kısa sürede yol alan motor modeli ortaya konulmuştur. 


\begin{tabular}{|c|c|c|}
\hline & $\begin{array}{l}\text { BŞEÜ Fen Bilimleri Dergisi } \\
8(2), 575-585,2021\end{array}$ & $\begin{array}{r}\text { BSEU Journal of Science } \\
\text { https://doi.org/10.35193/bseufbd.899158 }\end{array}$ \\
\hline $\begin{array}{l}\text { BiLCEKS SEYHEDEBAII } \\
\text { ONIVERSITESI }\end{array}$ & & 2458-7575 (https://dergipark.org.tr/tr/pub/bseufbd) \\
\hline
\end{tabular}

\section{YÖNTEM VE MOTOR MODELI}

Çalışmada modelleme kısmı iki aşamada gerçekleştirilmiştir. İlk aşamada referans motorun RMxprt programında tasarımı gerçekleştirilmiştir ve Matlab Simulink için gerekli olan motor parametreleri elde edilmiştir. İkinci aşamada ise motorların devir sayısı-yol alma süresi eğrilerinin elde edilebilmesi amacıyla Simulink modeli oluşturulmuştur. Referans motor modeline ait etiket değerleri Tablo 1' de verilmiştir.

Tablo 1. Referans motorun etiket değerleri [15]

\begin{tabular}{lc}
\hline Motor Parametreleri & Değer \\
\hline Güç [kW] & 13 \\
Gerilim [V] & 400 \\
Nominal Akım [A] & 21 \\
Kutup Sayısı & 4 \\
Nominal Devir Sayıs1 [d/d] & 1480 \\
Nominal Moment [N.m] & 83 \\
Frekans [Hz] & 50 \\
Bağlantı Şekli & Üçgen \\
\hline
\end{tabular}

Referans motorun genel kesit görüntüsü ve stator-rotor oluklarına ait detaylı gösterim Şekil 1' de verilmiştir. Motorun stator oluk sayısı 36, rotor oluk sayısı ise 46' dır. Rotor oluk yapısı damla şeklindeki oluk geometrisine sahipken stator oluk yapısı ise trapezoidal geometri şeklindedir. Motorun stator diş ve iç çapı sırasıyla $298 \mathrm{~mm}$ ve $184 \mathrm{~mm}$, rotor iç çap $160 \mathrm{~mm}$, paket boyu ise $123 \mathrm{~mm}$ ' dir. Stator ve rotor nüvesinde M19-24G malzemesi kullanılmıştır.

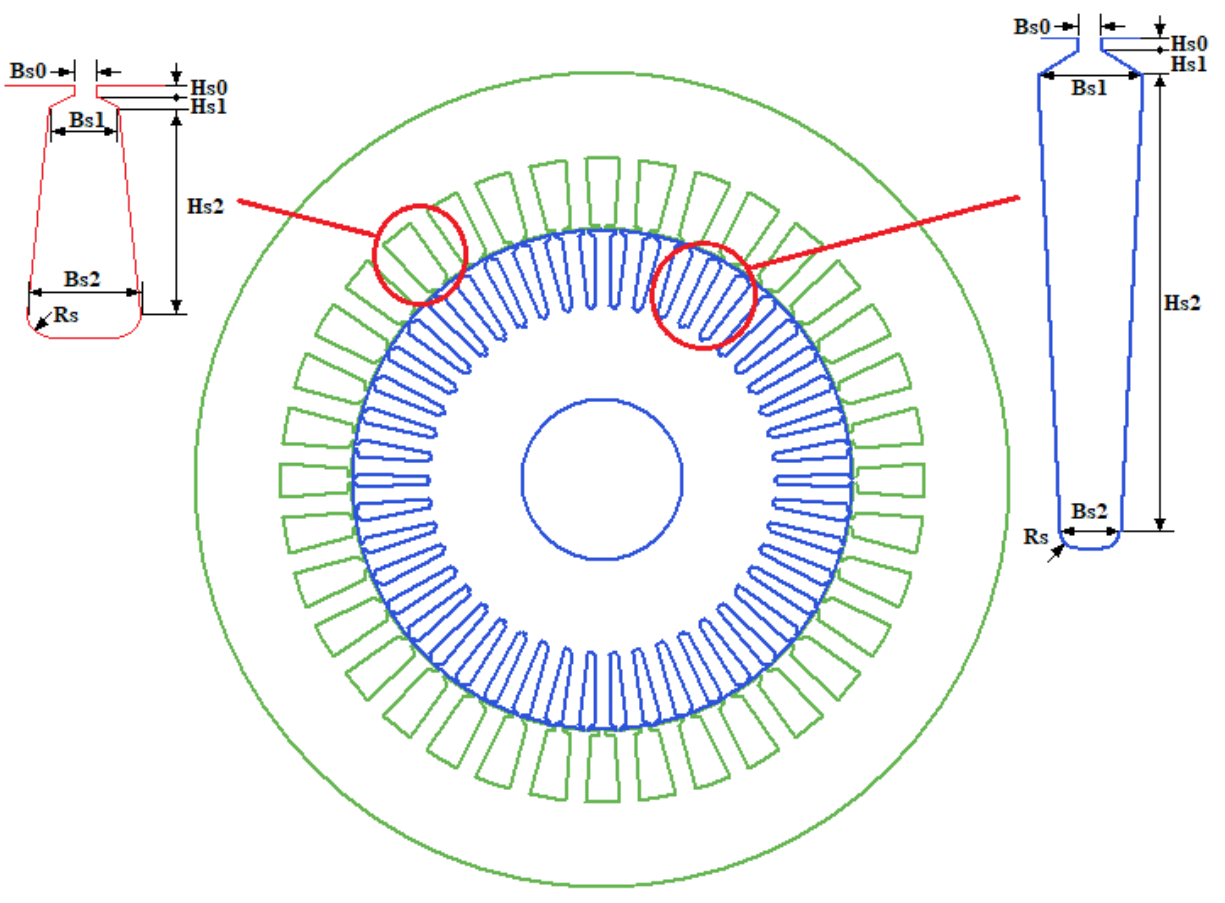

Şekil 1. Referans motor geometrisi ve oluk yapıları

Referans motorun stator ve rotor oluk yapılarına ait parametre ve değerleri Tablo 2' de verilmiştir. 
Tablo 2. Referans motorun stator ve rotor oluk geometri değerleri [15]

\begin{tabular}{lcc}
\hline Oluk Geometri Parametreleri & Stator [mm] & Rotor [mm] \\
\hline Oluk Ağız Açıklığı $(B s O)$ & 3.1 & 1.5 \\
Oluk Üst Genişliği $(B s 1)$ & 9 & 6 \\
Oluk Alt Genişliği $(B s 2)$ & 13.15 & 3.5 \\
Oluk Ağız Yüksekliği $(H s O)$ & 0.6 & 0.8 \\
Oluk Kama Yüksekliği $(H s 1)$ & 1.08 & 1.4 \\
Oluk Yüksekliği $(H s 2)$ & 23.82 & 25.3 \\
Oluk Dibi Yarıçapı $(R s)$ & 0 & 1 \\
\hline
\end{tabular}

Çalışmanın ikinci aşamasında, Şekil 2' de verilen Matlab Simulink modeli kullanılarak devir sayısı-yol alma süresinin değişimleri elde edilmiştir. Her bir motor modeline ayrı ayrı RMxprt modellerinden elde edilen stator ve rotor direnç ile reaktans değerleri, mıknatıslanma reaktansı, gerilim, güç, kutup sayısı gibi parametrelerin girilmesi ile devir sayısı-yol alma süresi grafikleri elde edilmiştir. Modellemelerde moment parametresi olarak nominal moment değerleri girilmiş ve analizler yapılmıştır. Asenkron motorların yol alma süresini minimum seviyeye çekmek ve yol alma akımını sınırlamak amacı ile literatürde birçok model ve yöntem mevcuttur [12, 1618]. Bu çalışmada ise asenkron motorun rotor oluk yüksekliğinin, hava aralığı boyunun ve farklı rotor oluk yapılarının etkisinin net bir şekilde görülebilmesi amacıyla Matlab Simulink modeli sadece kaynak, motor modeli ve rotor devir sayısının gösterildiği bir göstergeden meydana gelecek şekilde tasarlanmıştır.

Yol alma süresinin hesaplanmasında atalet momenti değerleri her bir motor modeli için farklı elde edilmiş (RMxprt modelinden) ve bu değerler Matlab Simulink modeline girilerek analizler yapılmıştır.

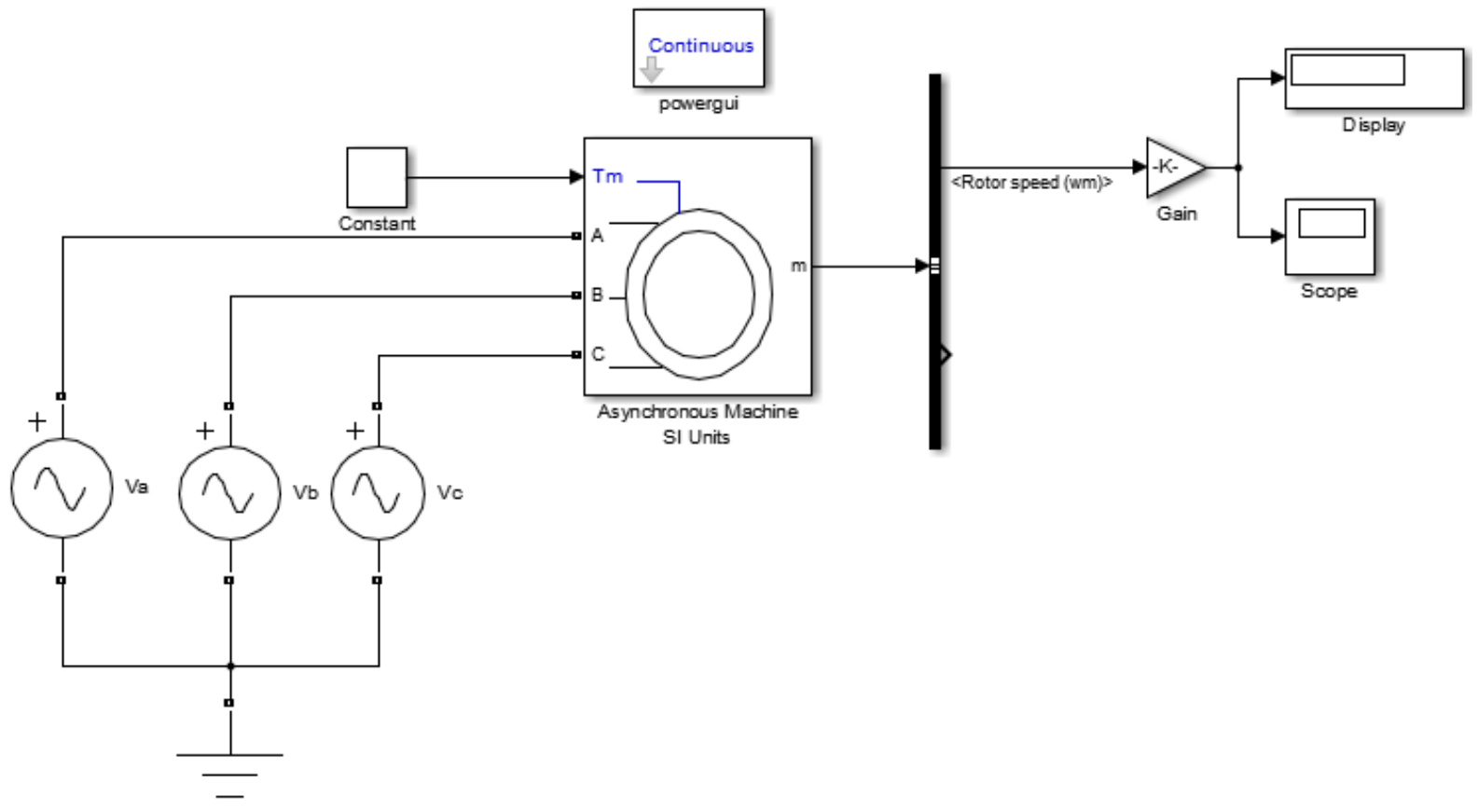

Şekil 2. Matlab Simulink modeli

Şekil 1' de verilen rotor oluk geometrisi için rotor oluk alanı $\left(A_{b}\right)$ Denklem 1 ile elde edilebilir. Rotor parametreleri ile ilgili diğer hesaplamalar detaylı bir şekilde [19]'dan elde edilebilir.

$$
A_{b}=\frac{\pi}{8}\left(b_{s 1}^{2}+b_{s 2}^{2}\right)+\frac{\left(b_{s 1}+b_{s 2}\right)\left(2 h_{s 2}-b_{s 1}-b_{s 2}\right)}{2}
$$




\begin{tabular}{|c|c|c|}
\hline & $\begin{array}{l}\text { BŞEÜ Fen Bilimleri Dergisi } \\
8(2), 575-585,2021\end{array}$ & $\begin{array}{r}\text { BSEU Journal of Science } \\
\text { https://doi.org/10.35193/bseufbd.899158 }\end{array}$ \\
\hline VERS & & 2458-7575 (https://dergipark.org.tr/tr/pub/bseufbd) \\
\hline
\end{tabular}

\section{ELDE EDİLEN SONUÇLAR}

Bu çalışmada üç fazlı bir asenkron motorun yol alma süresinin değişimi, rotor oluk yüksekliğinin etkisi, hava aralığı boyunun etkisi ve rotor oluk yapılarının etkisi olmak üzere 3 farklı kategoride incelenmiştir. Ayrıca motor modellerinin devir sayılarındaki salınım değişimleri de verilmiştir.

\section{A. Rotor Oluk Yüksekliğinin Etkileri}

Asenkron motorlardaki en kritik parametrelerden birisi de rotor oluk yapısıdır. Zira rotor sargısı kaçak reaktans ve direnç değeri motor performansı üzerinde oldukça etkilidir. Bu sebeple rotorun tek kafes mi, çift kafes mi olacağ1 veya rotor oluk geometri parametrelerinin belirlenmesi büyük önem arz etmektedir. Bu çalışmada referans motorun rotor oluk yükseklik değeri değiştirilerek motor yol alma süresinin değişimi incelenmiştir. Referans motorun rotor oluk yüksekliği (Hs2) 25.3 mm' dir. Oluk yüksekliğinin etkisinin görülebilmesi için bu değer 20 mm' den 29 mm' ye kadar 1'er mm olacak şekilde artırılmıştır. Modellemeler yapılırken stator dış çapı, rotor iç çapı, stator oluk geometrisi, sargı yapısı ve kullanılan malzemeler vb. parametreler sabit tutulmuştur.

Rotor oluk yükseklik değerleri için RMxprt modelinden elde edilen ve Matlab Simulink programında kullanılan eşdeğer devre parametrelerinin değerleri Tablo 3' de verilmiştir. Eşdeğer devre parametrelerinin değerleri ' $\Omega$ ' cinsinden verilmiştir.

Tablo 3. Rotor oluk yüksekliği değişimine göre eşdeğer devre parametreleri

\begin{tabular}{lccccc}
\hline Rotor Oluk Yüksekliği [mm] & $\mathbf{R}_{\mathbf{1}}$ & $\mathbf{R}_{\mathbf{2}}$ & $\mathbf{X}_{\mathbf{1}}$ & $\mathbf{X}_{\mathbf{2}}$ & $\mathbf{X}_{\mathbf{m}}$ \\
\hline 20 & & 0.164282 & 0.784659 & 0.750414 & 35.2236 \\
21 & & 0.159445 & 0.781178 & 0.756229 & 34.8261 \\
22 & & 0.155015 & 0.777513 & 0.761851 & 34.4063 \\
23 & & 0.150944 & 0.773645 & 0.767232 & 33.9653 \\
24 & $\widetilde{N}$ & 0.147189 & 0.769610 & 0.772439 & 33.5042 \\
25 & $\tilde{\sigma}$ & 0.143715 & 0.761624 & 0.773315 & 32.5920 \\
25.3 & $\widetilde{N}$ & 0.142723 & 0.760160 & 0.774602 & 32.4241 \\
26 & & 0.140492 & 0.756678 & 0.777525 & 32.0262 \\
27 & & 0.137493 & 0.751466 & 0.781434 & 31.4307 \\
28 & & 0.134695 & 0.745212 & 0.784200 & 30.7164 \\
29 & & 0.132080 & 0.737030 & 0.784851 & 29.7823 \\
\hline
\end{tabular}

Stator sargı direnci bütün motor modellerinde aynı kalmıştır. Bunun nedeni ise stator nüve, oluk ve sargı yapısı gibi parametrelerde herhangi bir değişiklik yapılmamasıdır. Elde edilen rotor oluk yükseklik değişimine göre stator ve rotor sargı setlerinde reaktans, mıknatıslanma reaktansı gibi değerlerde değişiklikler meydana gelmiştir. Ayrıca rotor oluk yüksekliğindeki artış rotor oluk alanının da \% 52’ lik (minimum ve maksimum oluk yüksekliği için) bir artışa neden olmuştur. Bu durum rotor direncinin azalması ile sonuçlanmıştır. Bu değişimlerin motor yol alma süresine etkileri Şekil 3' de verilmiştir. Motorun yol alma süresinin değişimi (0-1) saniye aralığında incelenmiştir. Motor modeline bağlı olarak, motor milinin maksimum ve minimum hız salınım değerleri ise Tablo 4' de verilmiştir. 

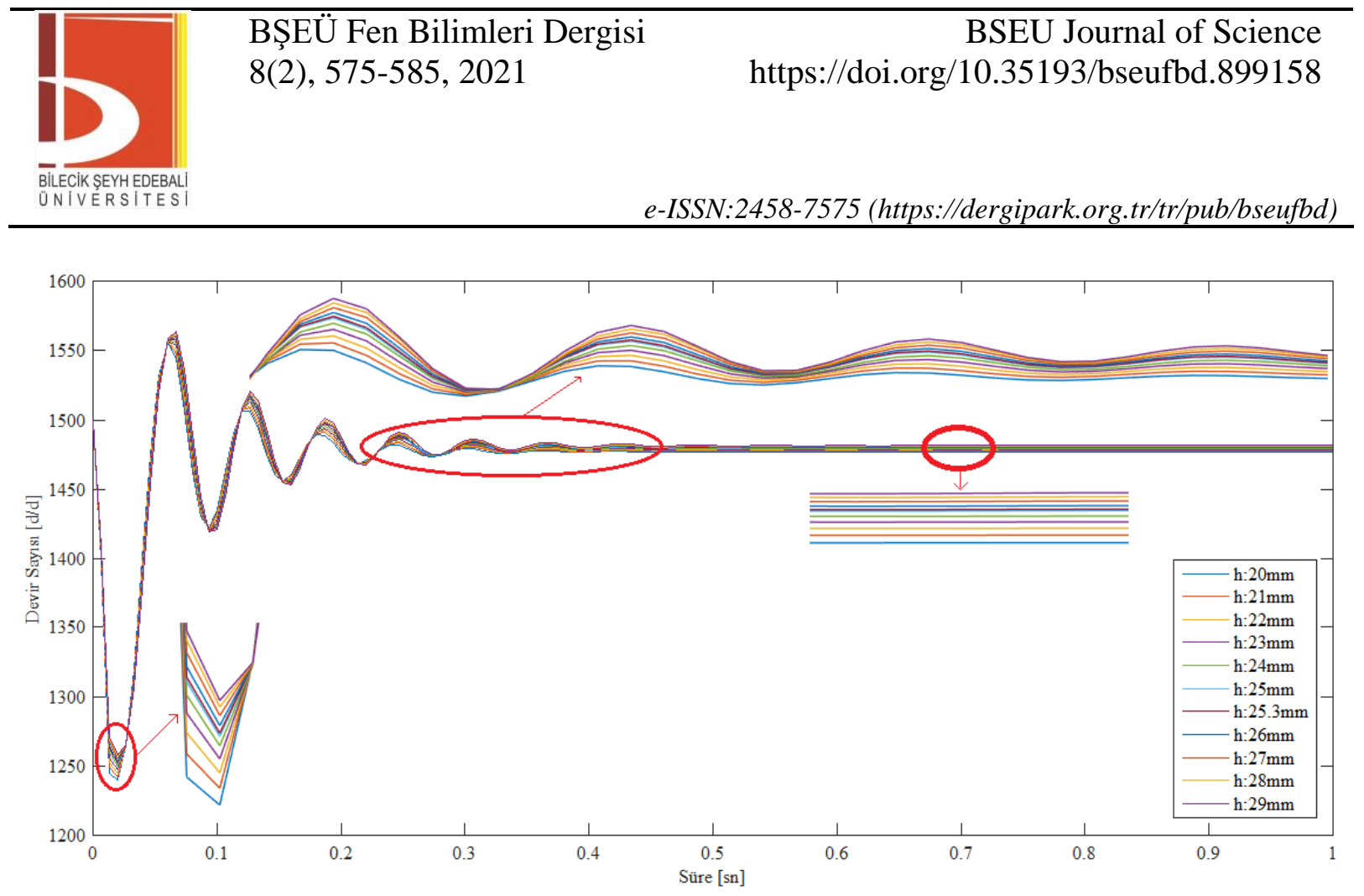

Şekil 3. Rotor oluk yüksekliğinin yol alma süresi-devir sayısı değişimleri

Tablo 4. Rotor oluk yükseklik değerlerine göre motor modellerinin motor mili hız salınım değerleri

\begin{tabular}{lcc}
\hline Rotor Oluk Yüksekliği [mm] & Maksimum Devir Sayısı [d/d] & Minimum Devir Sayısı [d/d] \\
\hline 20 & 1555.0203 & 1239.4083 \\
21 & 1555.9676 & 1242.4399 \\
22 & 1556.6177 & 1245.1957 \\
23 & 1557.0280 & 1247.7274 \\
24 & 1557.2341 & 1250.0655 \\
25 & 1557.9470 & 1251.7760 \\
25.3 & 1558.0690 & 1252.3450 \\
26 & 1559.3940 & 1253.7160 \\
27 & 1561.1090 & 1255.5210 \\
28 & 1562.5530 & 1257.0630 \\
29 & 1563.6890 & 1258.2400 \\
\hline
\end{tabular}

Motorun ilk yol alma anındaki hız salınım değerleri incelendiğinde rotor oluk yüksekliği $20 \mathrm{~mm}$ olan model en fazla hız salınımı yapan motor modeli olurken, en az hız salınımı ise rotor oluk yükseklik değeri $29 \mathrm{~mm}$ olan motor modelinden elde edilmiştir. Devir sayısının pik yapmış olduğu yani ikinci salınım kısmında 29 mm rotor oluk yüksekliğine sahip motor modelinin en yüksek salınım değerine sahip iken, $20 \mathrm{~mm}$ motor modelinin ise pik kısmındaki salınım değeri en az olmuştur. Diğer rotor oluk yüksekliklerinde bu değerlerin arasında hız salınımları elde edilmiştir. Ayrıca rotor oluk yükseklik değerinin artması ile beraber ortalama hız salınımı miktarında bir azalma olduğu anlaşılmaktadır. Asenkron motorun farklı rotor oluk yükseklikleri için elde edilen yol alma süresi değerleri Tablo 5' de verilmiştir. 


\begin{tabular}{|c|c|c|}
\hline & $\begin{array}{l}\text { BŞEÜ Fen Bilimleri Dergisi } \\
8(2), 575-585,2021\end{array}$ & $\begin{array}{r}\text { BSEU Journal of Science } \\
\text { https://doi.org/10.35193/bseufbd } 899158\end{array}$ \\
\hline & & 2458-7575 (https://dergipark.org.tr/tr/pub/bseufbd) \\
\hline
\end{tabular}

Tablo 5. Farklı rotor oluk yükseklik değerleri için elde edilen yol alma süreleri

\begin{tabular}{lc}
\hline Rotor Oluk Yüksekliği [mm] & Yol Alma Süresi [sn] \\
\hline 20 & 0.52000 \\
21 & 0.43333 \\
$\mathbf{2 2}$ & $\mathbf{0 . 4 0 6 6 6}$ \\
23 & 0.56000 \\
24 & 0.43333 \\
25 & 0.61333 \\
25.3 & 0.58666 \\
26 & 0.46666 \\
27 & 0.50000 \\
28 & 0.52666 \\
29 & 0.49333 \\
\hline
\end{tabular}

Tablo 5 incelendiğinde rotor oluk yükseklik değerinin değişimine göre yol alma sürelerinin de salınımlı olduğu görülmektedir. En uzun sürede yol alan motor modeli rotor oluk yüksekliğinin $25 \mathrm{~mm}$ olduğu model iken en kısa sürede yol alan motor modelinin ise $22 \mathrm{~mm}$ rotor oluk yüksekliğindeki model olduğu görülmektedir.

\section{B. Hava Aralığı Boyunun Etkisi}

Asenkron motorlarda hava aralığı boyu $(g)$ motor performansı üzerinde büyük bir etkiye sahiptir. Motorlarda hava aralığ küçük hava aralıkları mekanik olarak yapılması zor olmakla beraber, çok büyük hava aralıkları ise motor performansı (özellikle mıknatıslanma akımı) üzerinde negatif etkiye sahiptir. Bu sebeple hava aralığı boyunun motor performansını maksimum yapacak şekilde seçilmesine özen gösterilmesi gerekmektedir.

Bu çalışmada hava aralığı boyu $0.25 \mathrm{~mm}$ ' den $0.6 \mathrm{~mm}$ ' ye kadar artırılarak motorun yol alma süresindeki değişimler incelenmiştir. Stator ve rotor dişlerinde herhangi bir doyma meydana gelmemesi açısından hem stator iç çapı hem de rotor dış çapı aynı anda değiştirilerek hava aralığı boyları ayarlanmıştır. Motorun diğer parametrelerinde herhangi bir değişiklik yapılmamıştır.

Farklı hava aralığı boyları için RMxprt modelinden elde edilen ve Matlab Simulink programında kullanılan eşdeğer devre parametrelerinin değişimleri Tablo 6' da verilmiştir. Eşdeğer devre parametrelerinin değerleri ' $\Omega$ ' cinsinden verilmiştir. Referans motorun hava aralığı boyu $0.45 \mathrm{~mm}$ 'dir.

Tablo 6. Hava aralığı boyu değişimine göre eşdeğer devre parametreleri

\begin{tabular}{lccccc}
\hline Hava Aralığı Boyu [mm] & $\mathbf{R}_{\mathbf{1}}$ & $\mathbf{R}_{\mathbf{2}}$ & $\mathbf{X}_{\mathbf{1}}$ & $\mathbf{X}_{\mathbf{2}}$ & $\mathbf{X}_{\mathbf{m}}$ \\
\hline 0.25 & 0.265216 & 0.142798 & 0.830794 & 0.842458 & 42.2102 \\
0.3 & 0.265242 & 0.142779 & 0.814379 & 0.828266 & 39.5259 \\
0.35 & 0.265268 & 0.142761 & 0.798277 & 0.813785 & 37.1395 \\
0.4 & 0.265294 & 0.142742 & 0.779502 & 0.794761 & 34.7664 \\
0.45 & 0.265320 & 0.142723 & 0.760160 & 0.774602 & 32.4241 \\
0.5 & 0.265345 & 0.142704 & 0.743667 & 0.757393 & 30.4417 \\
0.55 & 0.265371 & 0.142686 & 0.728768 & 0.741818 & 28.6634 \\
0.6 & 0.265397 & 0.142667 & 0.715755 & 0.728203 & 27.1180 \\
\hline
\end{tabular}

Tablo 6 incelendiğinde eşdeğer devre parametrelerde en çok değişimin stator ve rotor kaçak reaktans değerlerinde ve mıknatıslanma reaktansında olduğu görülmektedir. Direnç değerlerinde net bir değişim olmadığı görülmektedir.

Hava aralı̆̆ boyunun motor yol alma süresine olan etkisi Şekil 4' de verilmiştir. Yol alma süresi (0-1) saniye için elde edilmiştir. Hava aralığı boyu değerlerine göre motor modellerinin motor mili hız salınım değerleri ise Tablo 7' de verilmiştir. 

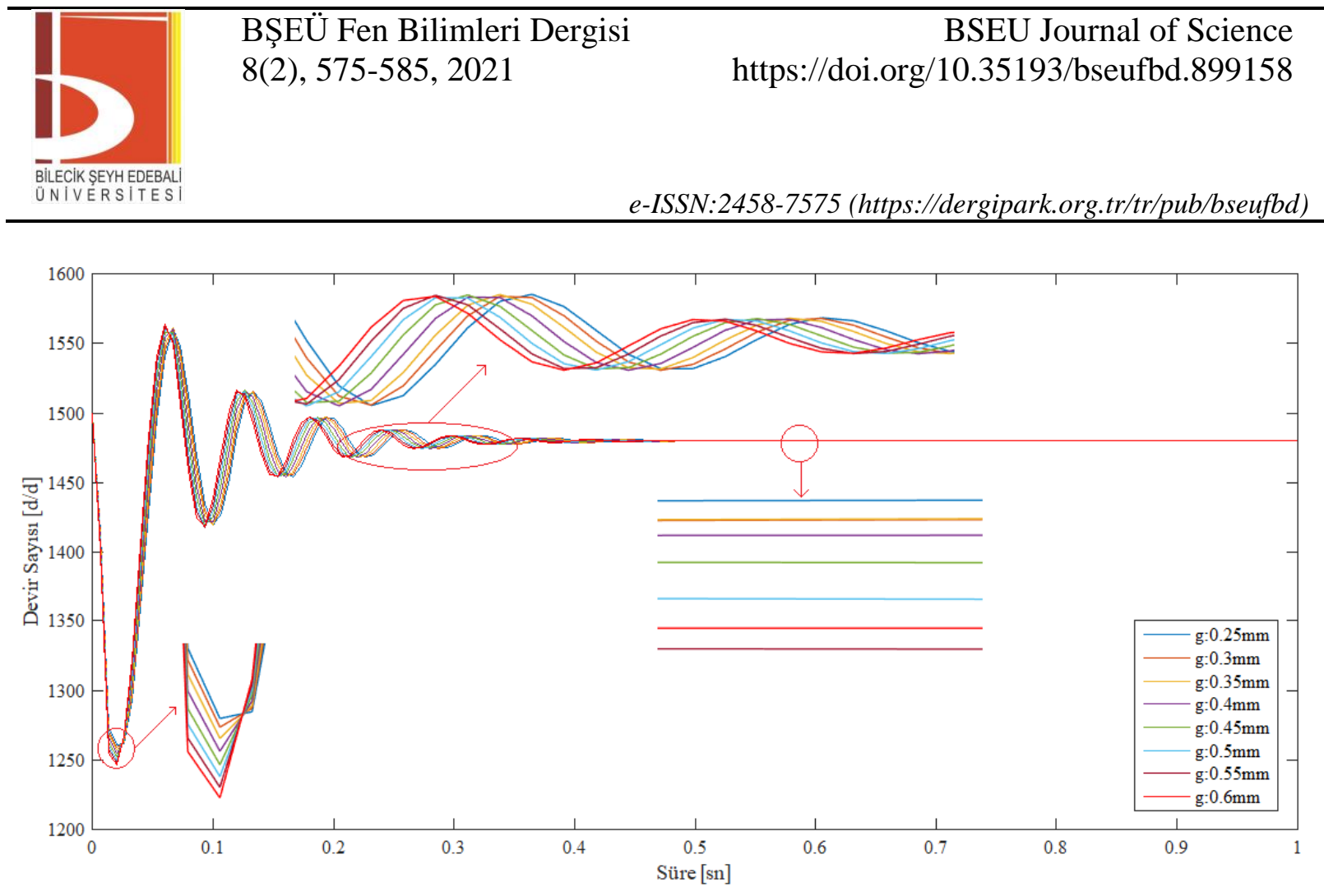

Şekil 4. Hava aralığı boyunun yol alma süresi-devir sayısı değişimleri

Tablo 7. Hava aralığı boyu değerlerine göre motor modellerinin motor mili hız salınım değerleri

\begin{tabular}{lcc}
\hline Hava Aralı̆̆ı Boyu [mm] & Maksimum Devir Sayısı [d/d] & Minimum Devir Sayısı [d/d] \\
\hline 0.25 & 1560.466 & 1260.659 \\
0.3 & 1560.948 & 1259.095 \\
0.35 & 1560.985 & 1257.054 \\
0.4 & 1560.084 & 1254.764 \\
0.45 & 1558.069 & 1252.345 \\
0.5 & 1560.638 & 1250.222 \\
0.55 & 1562.476 & 1248.291 \\
0.6 & 1563.750 & 1246.403 \\
\hline
\end{tabular}

Motorun yol alma anındaki salınım değerleri incelendiğinde hava aralığı boyunun $0.6 \mathrm{~mm}$ olduğu modelde en fazla salınımın meydana geldiği, $0.25 \mathrm{~mm}$ hava aralığı boyu olan modelde salınımın en küçük seviyede olduğu tespit edilmiştir. Devir sayısının maksimum olduğu noktadaki değerler incelendiğinde hava aralığının artması ile birlikte bu değerinde arttığı görülmektedir. Ayrıca hava aralığı boyu değerinin artması ile beraber salınım miktarında bir artış olduğu anlaşılmaktadır. Hava aralığı boyu değerleri için elde edilen motor yol alma süreleri Tablo 8' de verilmiştir.

Tablo 8. Farklı hava aralı̆̆ı boyu değerleri için elde edilen yol alma süreleri

\begin{tabular}{|c|c|}
\hline Hava Aralığı Boyu [mm] & Yol Alma Süresi [sn] \\
\hline 0.25 & 0.55333 \\
\hline 0.3 & 0.54666 \\
\hline 0.35 & 0.59333 \\
\hline 0.4 & 0.59333 \\
\hline 0.45 & 0.58666 \\
\hline 0.5 & 0.58000 \\
\hline 0.55 & 0.62666 \\
\hline 0.6 & 0.56666 \\
\hline
\end{tabular}




\begin{tabular}{|c|c|c|}
\hline & $\begin{array}{l}\text { BŞEÜ Fen Bilimleri Dergisi } \\
8(2), 575-585,2021\end{array}$ & $\begin{array}{r}\text { BSEU Journal of Science } \\
\text { https://doi.org/10.35193/bseufbd } 899158\end{array}$ \\
\hline VERS & & :2458-7575 (https://dergipark.org.tr/tr/pub/bseufbd) \\
\hline
\end{tabular}

Tablo 8 incelendiğinde hava aralı̆̆ı boyu 0.55 mm olan motor modeli en uzun yol alma süresine sahipken, en kısa sürede yol alan motor modeli ise hava aralığı boyu $0.3 \mathrm{~mm}$ olduğu görülmektedir. Referans motor modelinin ise 0.58666 saniyede yol aldığı görülmektedir. Genel olarak hava aralığı boyunun artması ile çok küçük bir oranda yol alma süresinin arttığı anlaşılmaktadır.

\section{Rotor Oluk Geometrisinin Etkisi}

Asenkron motor tasarım sürecinde en kritik parametrelerden birisi de rotor oluk geometrisidir. Rotor oluk geometrisinin değişik yapıda olması rotor direncinin de değişmesine neden olmaktadır ve bu durum motor performansını diğer parametrelere göre daha fazla etkilemektedir. Özellikle aynı çıkış gücüne sahip motorlardan, farklı yol alma akımları, yol alma momentleri ve devir sayıları elde edilebilmektedir. NEMA (Ulusal Elektrik Üreticileri Birliği) rotor oluk geometrilerini A, B, C ve D sınıfı olmak üzere dört grupta toplamıştır [20].

Çalışmanın bu kısmında NEMA tasarım sınıfında yer alan A, B, C ve D sınıfı rotor oluk geometrilerinin motorun yol alma süresine etkileri incelenmiş̧ir. Elde edilen eşdeğer devre parametrelere değerleri Tablo 9' da verilmiştir. Motorun stator ve sargı yapısı ile ilgili herhangi bir değişiklik yapılmamıştır.

Tablo 9. Rotor oluk geometri değişimine göre eşdeğer devre parametreleri

\begin{tabular}{lccccc}
\hline Rotor Oluk Geometrisi & $\mathbf{R}_{\mathbf{1}}$ & $\mathbf{R}_{\mathbf{2}}$ & $\mathbf{X}_{\mathbf{1}}$ & $\mathbf{X}_{\mathbf{2}}$ & $\mathbf{X}_{\mathbf{m}}$ \\
\hline NEMA-A & & 0.148728 & 0.763827 & 0.743304 & 32.8428 \\
NEMA-B & & 0.143770 & 0.770217 & 0.784095 & 33.5739 \\
NEMA-C & 0.26532 & 0.154752 & 0.758177 & 0.708188 & 32.1972 \\
NEMA-D & & 0.233170 & 0.725065 & 0.526577 & 28.4159 \\
\hline
\end{tabular}

Tablo 9 incelendiğinde rotor oluk geometrisine göre elde edilen eşdeğer devre parametrelerinde rotor ile ilgili parametrelerde farklılıkların olduğu görülmektedir. Bu durum rotor geometrisine ait oluk genişlik, yükseklik gibi parametrelerin her bir oluk yapısı için farklı olmasından kaynaklanmaktadır. Şekil 5' de farklı rotor oluk geometrilerinin devir sayıs1-yol alma süresi değişimleri verilmiştir.

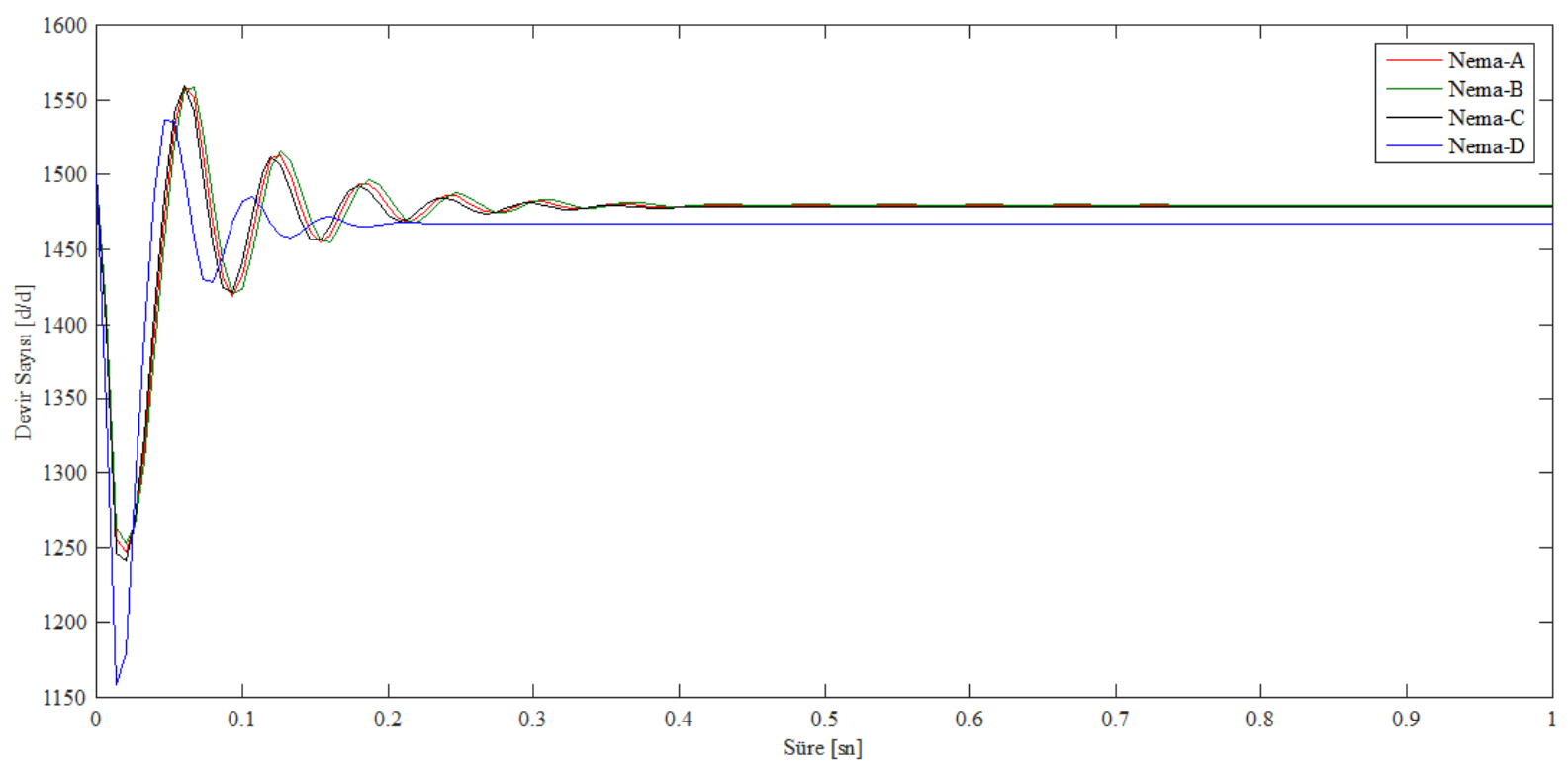

Şekil 5. Rotor oluk geometrilerine göre yol alma süresi-devir sayısı değişimleri

Şekil 5 incelendiğinde NEMA A, B ve C rotor oluk geometrilerinin salınım değişimlerinin birbirlerine yakın elde edildiği görülmekte iken, NEMA-D sınıfına ait rotor oluk geometrisinin salınım değerlerinin diğerlerine göre farklı elde edildiği görülmektedir. Ayrıca yine NEMA-D rotor oluk geometrisinin diğer rotor oluk yapılarına göre daha düşük devir sayısı ile döndüğü görülmektedir. Rotor oluk geometri değerlerine göre motor modellerinin motor mili hız salınım değerleri Tablo 10' da verilmişsir. 


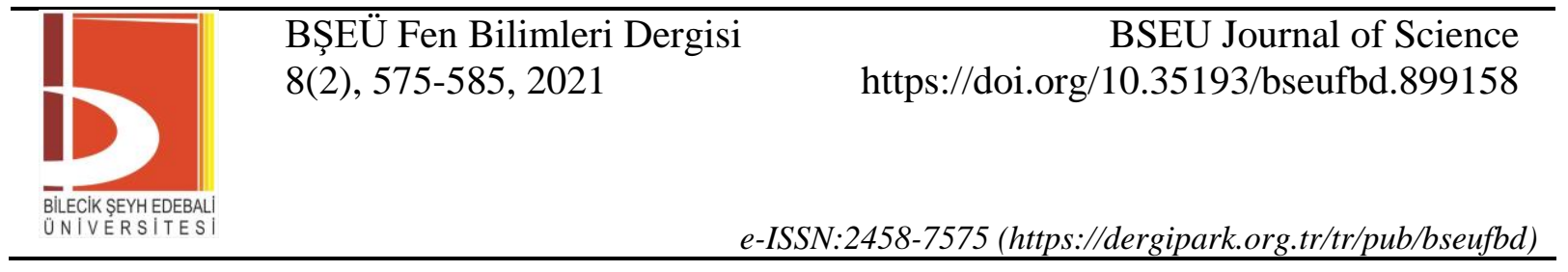

Tablo 10. Rotor oluk geometri değerlerine göre motor modellerinin motor mili hız salınım değerleri

\begin{tabular}{lcc}
\hline Rotor Oluk Geometrisi & Maksimum Devir Sayısı [d/d] & Minimum Devir Sayısı [d/d] \\
\hline NEMA-A & 1559.54269 & 1247.04287 \\
NEMA-B & 1558.60407 & 1252.92285 \\
NEMA-C & 1559.70625 & 1240.77246 \\
NEMA-D & 1536.41401 & 1158.69085 \\
\hline
\end{tabular}

Tablo 10 incelendiğinde NEMA-D sınıfı rotor oluk geometrisinin minimum ve maksimum salınım noktalarında diğer üç rotor oluk geometrisine göre elde edilen hız değerinin net bir şekilde farklı çıktığ anlaşılmaktadır. Buna rağmen daha az salınım yaparak nominal devir sayısına ulaştığı görülmektedir. NEMA A, $\mathrm{B}, \mathrm{C}$ ve D rotor oluk geometrileri için elde edilen yol alma süreleri Tablo 11' de verilmiştir.

Tablo 11. Rotor oluk geometri değerleri için elde edilen yol alma süreleri

\begin{tabular}{lc}
\hline \multicolumn{1}{c}{ Rotor Oluk Geometrisi } & Yol Alma Süresi [sn] \\
\hline NEMA-A & 0.46 \\
NEMA-B & 0.62 \\
NEMA-C & 0.40 \\
NEMA-D & $\mathbf{0 . 2 5 3 3 3}$ \\
\hline
\end{tabular}

Tablo 11 incelendiğinde en düşük yol alma süresinin NEMA-D sınıfı rotor oluk geometrisi olduğu, en uzun sürede yol alan geometrinin ise NEMA-B olduğu görülmektedir. NEMA-D ile NEMA-B sinıfı rotor geometrilerinin yol alma süreleri arasında neredeyse 2.5 katı fark olduğu görülmektedir. Bu durum motor gücünün büyümesi ile birlikte artan akımın sınırlandırılmasını zorunlu kılmaktadır.

\section{SONUÇLAR}

Bu çalışmada 3 fazlı sincap kafesli bir asenkron motorun yol alma süresi; rotor oluk yükseklik değeri, hava aralığı boyu ve rotor oluk geometrisi olmak üzere üç farklı kategoride incelenmiştir. Bununla beraber motor modellerinin minimum ve maksimum salınım yaptıkları değerler elde edilmiştir.

Rotor oluk yükseklik değerlerinin değiştirilmesi ile elde edilen motorun yol alma süreleri incelendiğinde en düşük yol alma süresinin 22 mm yükseklik değerine sahip olan motor modelinden elde edildiği görülmektedir. Rotor oluk yükseklik değerinin artması ile birlikte yol alma süresinde de bir miktar artışın olduğu görülmektedir. Hava aralığ 1 boyunun değiştirilmesi sonucunda asenkron motorun yol alma süresi değişimlerinde net bir farklılık göze çarpmaz iken, hava aralığı boyunun artması ile sürenin de bir artış eğiliminde olduğu görülmüştür. Yol alma süresinde en belirgin değişimler farklı rotor oluk geometrilerinin modellenmesi ile elde edilmiştir. Özellikle rotor olukları yüzeye daha yakın olan NEMA-D sınıfı tasarım modeli en kısa sürede yol alan motor olmuştur. En uzun sürede yol alan model ise NEMA-B rotor geometrisine sahip model olmuştur.

\section{KAYNAKLAR}

[1] Pejovski, D., \& Velkovski, B. (2016). Calculation of induction motor starting parameters using MATLAB. Infoteh-Jahorina, 15, 879-884.

[2] Garg, A., \& Tomar, A. (2015). Starting time calculation for induction motor. Journal of Electrical \& Electronic Systems, 4(2), 1-4.

[3] Khoucha, F., Marouani, K., Kheloui, A., \& Benbouzid, M. E. H. (2006). A Minimization of Speed Ripple of Sensorless DTC for controlled Induction Motors used in Electric Vehicles. 32nd Annual Conference on IEEE Industrial Electronics, 6-10 November, Paris, France, 1339-1344.

[4] Otkun, Ö. (2020). Scalar speed control of induction motors with difference frequency, Journal of Polytechnic, 23(2), 267-276.

[5] Sadhwani, R., \& Ragavan, K. (2016). A Comparative Study of Speed Control Methods for Induction Motor Fed by Three Level Inverter. 1st IEEE International Conference on Power Electronics, Intelligent Control and Energy Systems (ICPEICES-2016), 4-6 July, Delhi, India, 1-6. 
[6] Kocman, S., Orsag, P., \& Pecinka, P. (2017). Simulation of start-up behaviour of induction motor with direct online connection. Power Engineering and Electrical Engineering, 15(5), 754-762.

[7] Firago, B., \& Vasilyev, D. (2012). Soft starting and braking application for squirrel-cage induction motors operating in intermittent duty. Studia I Materialy, 66, 339-349.

[8] Popa, G. N., Popa, I., Dinis, C. M., \& Iagar, A. (2010). Determining Start Time for Three-Phase Cage Induction Motors that Drive Belt Transport Conveyers. 12th International Conference on Optimization of Electrical and Electronic Equipment, 447-452.

[9] Aree, P. (2016). Starting Time Calculation of Large Induction Motors Using their Manufacturer Technical Data. 19th International Conference on Electrical Machines and Systems (ICEMS), 13-16 November, Chiba, Japan, 1-5.

[10] Calasan, M. P. (2020). An invertible dependence of the speed and time of the induction machine during noload direct start-up. Automatika, 61(1), 141-149.

[11] Grover, S., \& Mankar, M. (2019). Minimization of starting torque and inrush current of induction motor by different starting methods using matlab/simulink. International Journal of Trend in Scientific Research and Development (IJTSRD), 3(3), 646-651.

[12] Kim, Y. S. (2015). Analysis of starting torque and speed characteristics for squirrel cage induction motor according to material properties of rotor slot. Transactions on Electrical and Electronic Materials, 16(6), 328-333.

[13] Ansys Maxwell 2D User's Guide, 2012.

[14] Mathworks, Simulink, Simulation and Model-Based Design, 2004.

[15] Plesinger, J. (2015). Brushless DC traction motor $13 \mathrm{~kW}$ with permanent magnets. Czech Technical University in Prague, Faculty of Electrical Engineering, Czechia.

[16] Bao, X.,Di, C., \& Fang, Y. (2016). Analysis of slot leakage reactance of submersible motor with closed slots during starting transient operation. Journal of Electrical Engineering \& Technology,11(1), 135-142.

[17] Bernatt, J., \& Bernatt, M. (2013). High power squirrel cage motors for heavy starting conditions. Przeglad Elektrotechniczny, R.89(2a), 25-27.

[18] Aree, P. (2018). Precise analytical formula for starting time calculation of medium and high-voltage induction motors under conventional starter methods. Electrical Engineering, 100, 1195-1203.

[19] Boldea, I., \& Nasar, S. A. (2002). The Induction Machine Handbook, Crc Pres Llc, Washington.

[20] Jeon, K. W., Chung, T. K., \& Hahn, S. C. (2011). NEMA Class a Slot Shape Optimization of Induction Motor for Electric Vehicle Using Response Surface Method. IEEE International Conference on Electrical Machines and Systems. 20-23 August, Beijing, China, 1-4. 